\title{
Seed Quality and Vigour Assessment of Fennel (Foeniculum vulgare L.) Genotypes
}

\author{
Sumit Deswal", V.S. Mor, T.P. Malik, S.K. Tehlan and Srikanth Mekala \\ Department of Vegetable Science, CCS Haryana Agricultural University, \\ Hisar-125004, Haryana, India \\ *Corresponding author
}

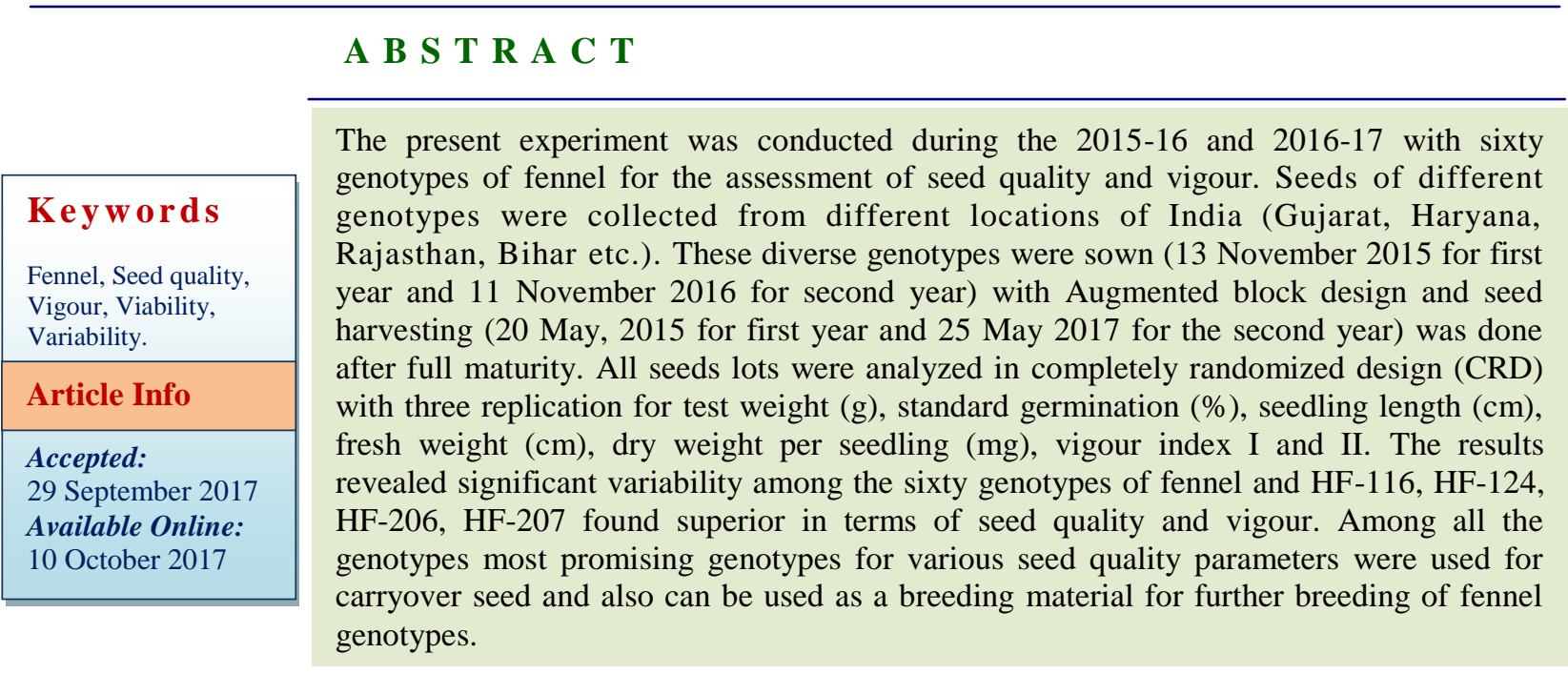

\section{Introduction}

Fennel (Foeniculum vulgare L.) is a biennial medicinal and aromatic plant belonging to the family Apiaceae (Umbelliferaceae). It is a hardy, perennial-umbelliferous herb with yellow flowers and feathery leaves. The flowers are produced in terminal compound umbels. The fruit is a dry seed $4-10 \mathrm{~mm}$ long. The seeds of fennel have an active substance, which is called essential oil and most important constituent is anethole that is used in pharmaceutical, food, perfumery and favoring industry (Miraldi, 1999; Sephidkon, 2001). Fennel essential oil possesses valuable antioxidant, and has antibacterial, anticancer and antifungal activity (Lucinewton et al., 2005; El-Alwadi and Esmat, 2010).
Mature fennel fruits are used as flavoring agents in food products such as pickles, liqueurs, bread, pastries and cheese (Zoubiri et al., 2014).Fennel fruits are used in diseases like cholera, nervous disorders, constipation, dysentery and colic pain. Fennel also contains minerals and vitamins like calcium, potassium, sodium, iron, phosphorus, thiamine, riboflavin and vitamin $\mathrm{C}$. By virtue of its finest quality and high vitamin content, demand of export due to its high quality seed is increasing steadily. The quality seed is prerequisite to enhance the production and productivity. Use of quality seeds increased productivity of crop by $15-20 \%$ (Sidhawani, 1991). The quality of seed is mainly measured 
by its genetic purity and capacity to develop into a healthy plant. Further, due to high value of seed spices, the quality of seeds becomes more important. This is mainly measured by its high genetical and physical purity, free from insect-pest and diseases, high vigour, germination percentage and uniformity in appearance. The advantages of high vigour seed are most often associated with rapid and high rate of emergence and stand establishment. There is also a need to have some more reliable parameters that evaluate the seed quality before it is sown in the field. Therefore, an attempt has been made to evaluate the fennel genotypes for the seed quality and vigour.

\section{Materials and Methods}

The present experiment was carried out during 2015-16 and 2016-17 at Chaudhary Charan Singh Haryana Agricultural University, Hisar. The field experimental site was located at between $29.15^{\circ} \mathrm{N}$ latitude $75.69^{\circ} \mathrm{E}$ longitude with a mean altitude of 215 $\mathrm{m}$ above msl. Sixty germplasms of fennel were studied for the experiment. The seeds are collected from different locations of India (Gujarat, Haryana, Rajasthan, Bihar etc.). These diverse genotypes were sown (13 November 2015 for first year and 11 November 2016 for second year) with Augmented block design having four blocks with fifteen entries in each block and having plot size of $3.0 \mathrm{~m} \times 1.0 \mathrm{~m}$ with spacing of 50 $\mathrm{cm} \times 20 \mathrm{~cm}$. All recommended agronomic practices were followed timely for successful raising the crop. Seed harvesting (20 May, 2015 for first year and 25 May 2017 for the second year) was done after full maturity and seeds were sun dried for 3 to 4 days in the field. After proper drying, cleaning and attaining the optimum moisture content the seeds were collected and the completely randomized design (CRD) was followed to conduct laboratory testing for the seed quality parameters in the seed testing laboratory, Department of Seed Science and Technology, CCS Haryana Agricultural University, Hisar.

The observations recorded on seed quality parameters were test weight, standard germination, seedling length $(\mathrm{cm})$ and seedling dry weight $(\mathrm{mg})$, vigour index-I and Vigour index-II. Test weight: From each genotype seed lot, 1000 seeds were counted and weight was calculated in gram.

Standard germination (\%): Hundred seeds per replication for individual genotypes were placed separately between two layers of moist germination paper (BP) and then kept in seed germinator at $20^{\circ} \mathrm{C}$. The final count of normal seedlings was made on the $21^{\text {st }}$ day and expressed as per cent germination.

Seedling length $(\mathrm{cm})$ : The seedling length was measured for ten randomly selected normal seedlings taken from three replications of standard germination test and recorded in centimeter. At last, average of ten seedlings was taken for final calculation.

Seedling dry weight (mg): Ten normal seedlings selected for measuring seedling length were further kept in hot air oven for taking dry weight. These are dried at $80^{\circ} \mathrm{C}$ for $48 \mathrm{~h}$ and then seedling dry weight was recorded in milligram. The average weight of ten seedlings was taken for further calculations.

Vigour indices: The vigour indices were calculated according to the following formulae suggested by Abdul Baki and Anderson (1973).

Vigour Index - I: Standard germination (\%) x Average seedling length $(\mathrm{cm})$

Vigour Index - II: Standard germination (\%) $\mathrm{x}$ Average seedling dry weight (mg) 


\section{Results and Discussion}

The weight of 1000 seeds denotes the extent of development of seed and is an important yield attribute besides contributing towards yield and quality of the seed.All the genotypes test weight and overall all mean of sixty genotypes for the 2015-16 and 2016-17 were presented in fig-1. It is revealed that overall mean during 2015-16(4.77 g) is slightly higher than 2016-17 (4.58). Genotype HF-120 (3.03g) recorded with lightest weight and HF-116 (6.37 g) was found to be heavier. Similarly, Sengupta (2011) in fenugreek, Yadav (2016) in coriander and Tanuj (2014) in fennel assess the different genotypes on the basis of test weight and found variability in test weight of different genotypes. Test weight is an important seed quality test as it represents the sample of crop and will give an indication to compares the seed quality standards. Standard germination test is an acceptable measure of seed quality and it provides information about emergence capacity of lots under favorable conditions (ISTA, 2003). Standard germination percentage demonstrate the significant variations (fig-2) among all the genotypes. The maximum germination $(92.01 \%)$ was observed in seeds harvested from the genotype HF-124 followed by $\mathrm{HF}$ 202(92.0\%) HF-115 (91.55 \%), HF-210 (91.33\%), HF-125 (91.01\%), and HF-109 $(90.0 \%)$ while the minimum germination $(84.6 \%)$ was observed in seeds harvested from the genotypes HF-105. The overall mean during 2015-16(88.80\%) is slightly lower than 2016-17 $(89.0 \%)$. The results indicating that most of genotypes with more test weight and size of seed bear better germination percentage, however, this is not true in respect of each genotype. Similarly, Pereira et al., (2008) mentioned that increase in seed germination and development is owing to the higher seed size, weight and density. Seeds with fully mature embryos and high amounts of food reserves are potentially the most germinative and vigorous ones (Carvalho and Nakagawa, 1983). Decrease in germination percentage of seeds of some genotypes might be due to reduced $\alpha$-amylase activity and carbohydrate contents (Bailly, 2004). Sprouting and birth of seedlings require lots of energy obtainable through oxidation of nutrients already stored inside the seed thus a high test weight seed of Salvia L. brings higher rates of sprouting Afshari et al., (2011). Significant differences were observed among the genotypes with respect to seedling length $(\mathrm{cm})$ and seedling dry weight $(\mathrm{mg})$.

The maximum value for seedling length in centimeter (19.35) registered in genotype HF206 (fig-3), whereas, the minimum value for seedling length (12.25) was registered with the genotype PF-35. The highest mean value for seedling dry weight in milligram (4.66) was recorded in genotypeHF-206, whereas, the lowest mean value for seedling dry weight (2.16) was recorded in PF-35 (fig-4). Results indicating that most genotypes with more test weight and size of seed bear higher seedling length and seedling dry weight. Large and heavy seeds have a competitive advantage over smaller and light seeds by having higher germination rates and greater nutrient reserves for the young seedlings, which enables the seedlings to grow larger and vigorous to tap resources earlier than their small-seeded counterparts (Flenner, 1983; Milberg et al., 1996 and Soltani et al., 2002). However, a negative relationship between seed size and germination percentage, root and shoot length was also reported by Kaya et al., (2008). Kapoor et al., 2010 reported that seedling growth is the morphogenetic expression of genetic programming. Significant variations were recorded in all the genotypes with respect to seed vigour index-I and II. The maximum value for vigour index-I (1742.99) was registered in seeds extracted from HF207 and the minimum value for vigour indexI (1090) was recorded in seeds extracted from the genotypes PF-35 (fig-5). 
Fig.1 Test Weight of genotypes (A, B, C) and overall mean of genotype (D)
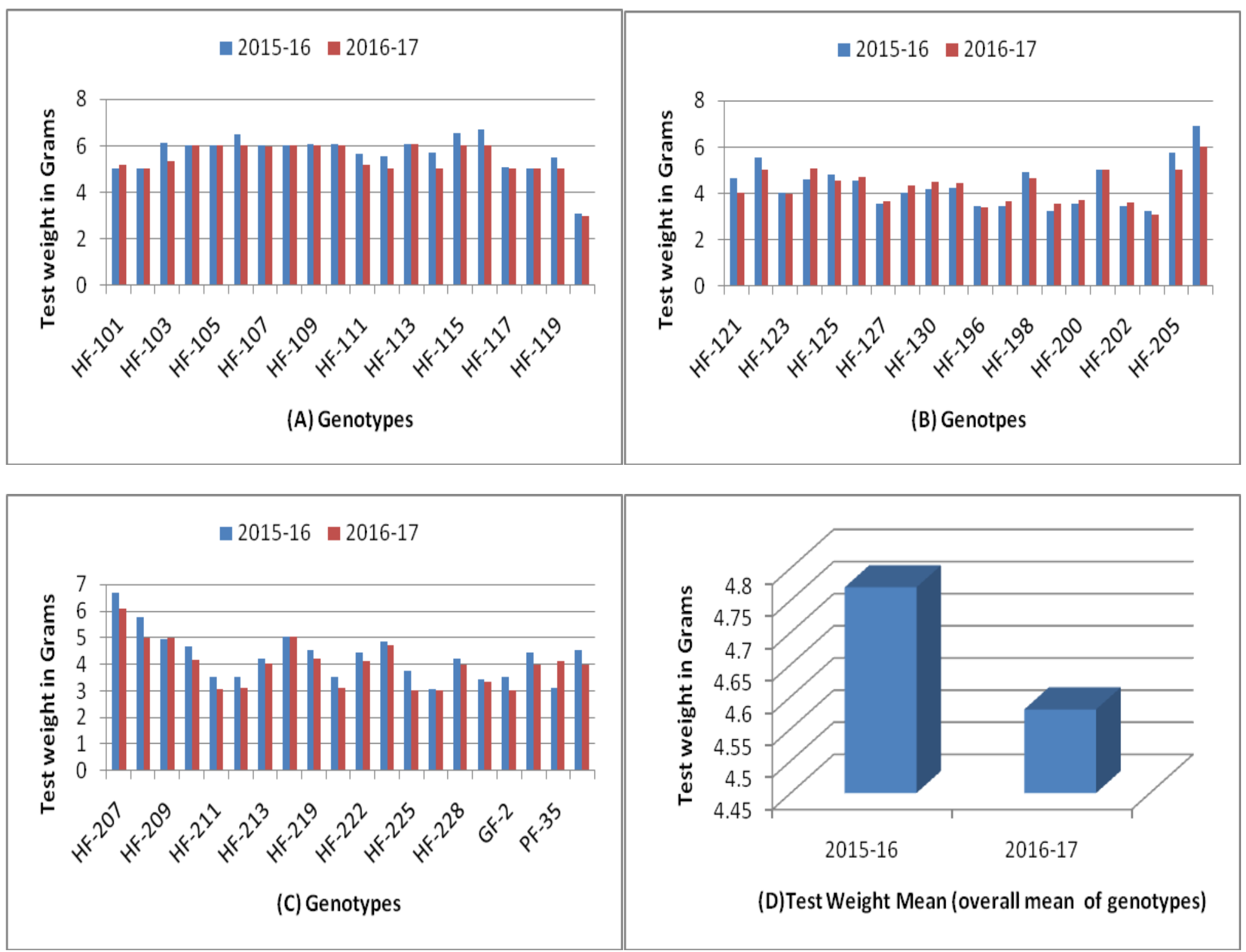
Fig.2 Standard germination percentage of genotypes (A, B, C) and overall mean of genotypes (D)
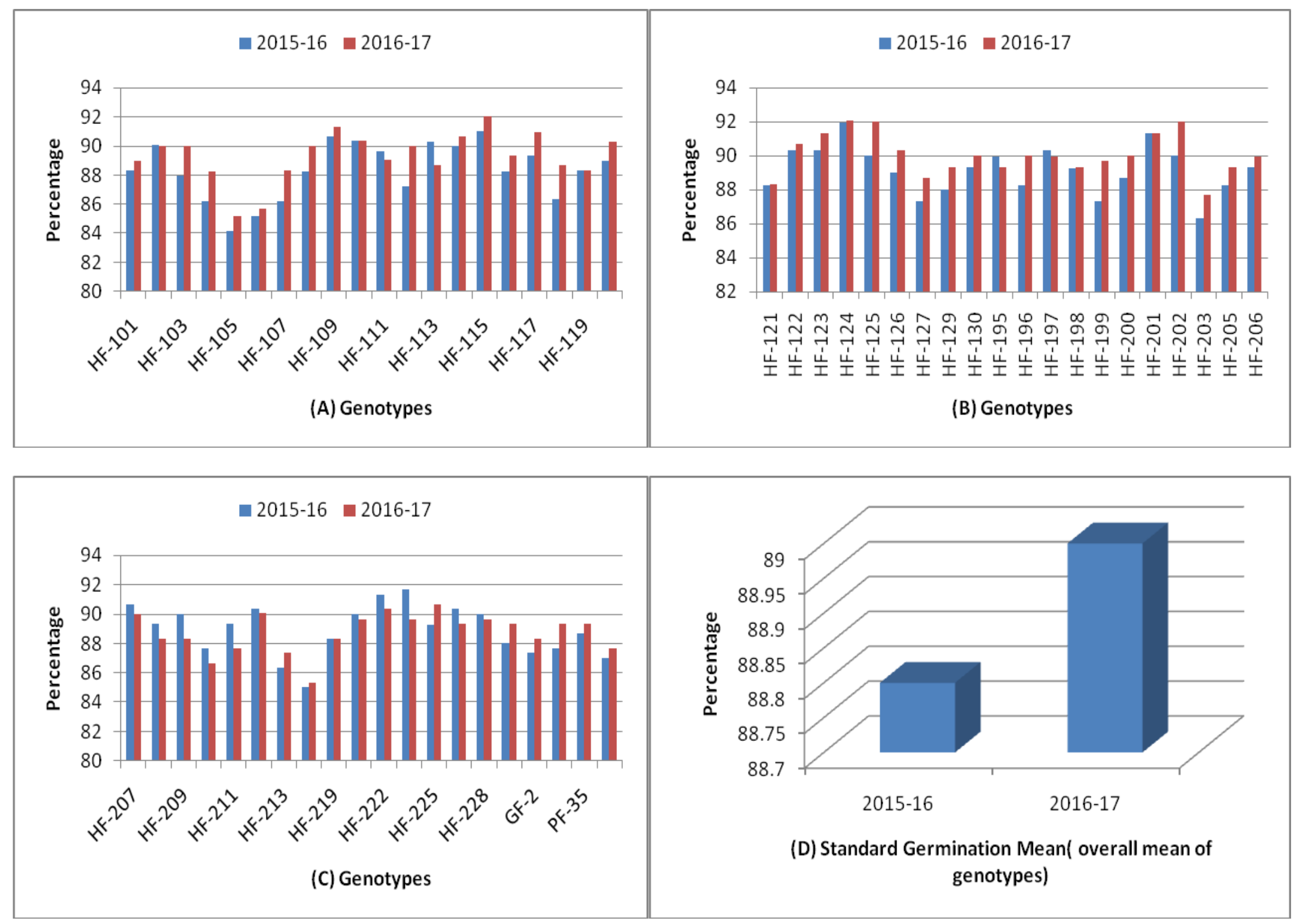


\section{Int.J.Curr.Microbiol.App.Sci (2017) 6(10): 4970-4980}

Fig.3 Seedling length (cm) of genotypes (A, B, C) and overall mean of genotypes (D)
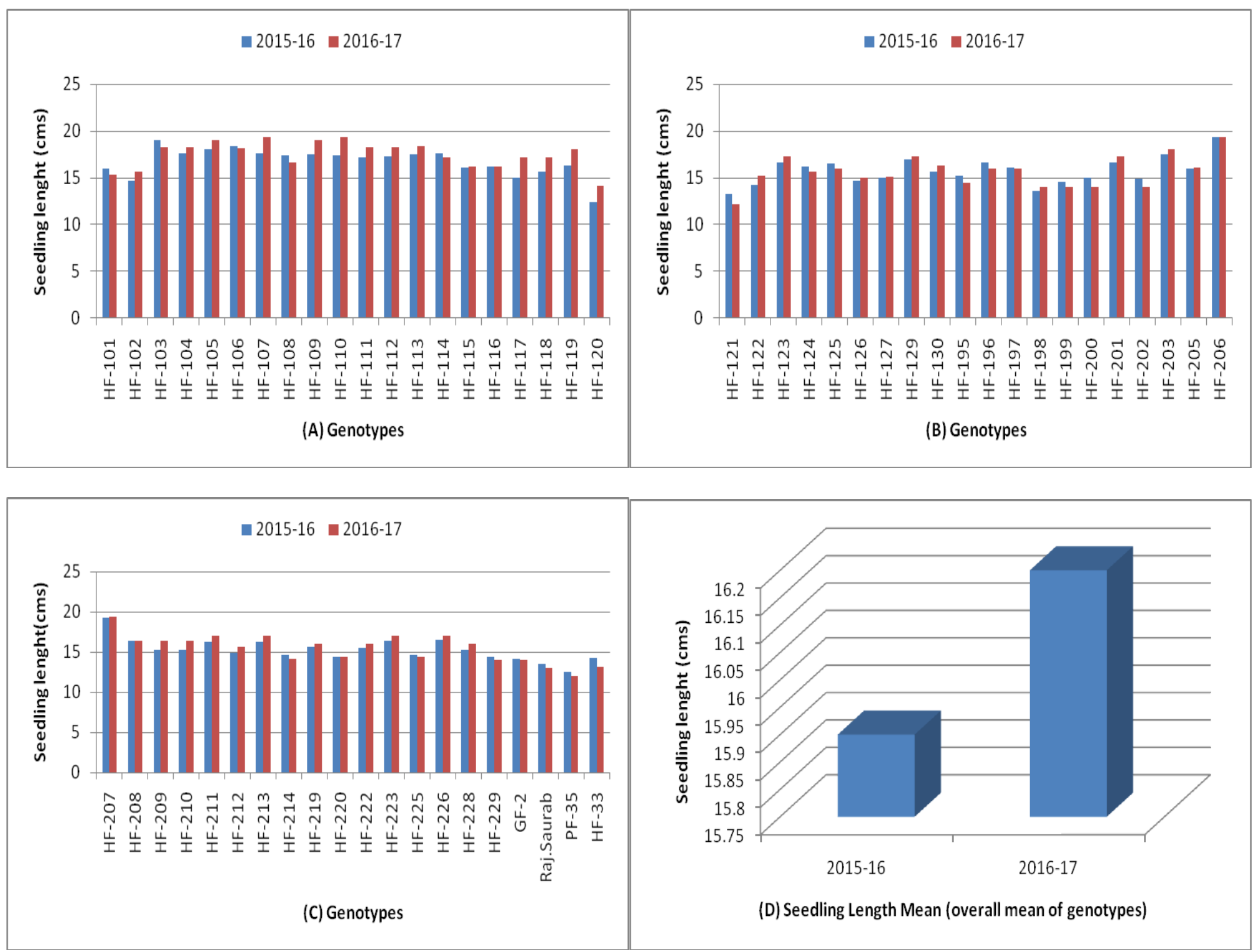
Fig.4 Dry weight (mg) of genotypes (A, B, C) and overall mean of genotypes (D)
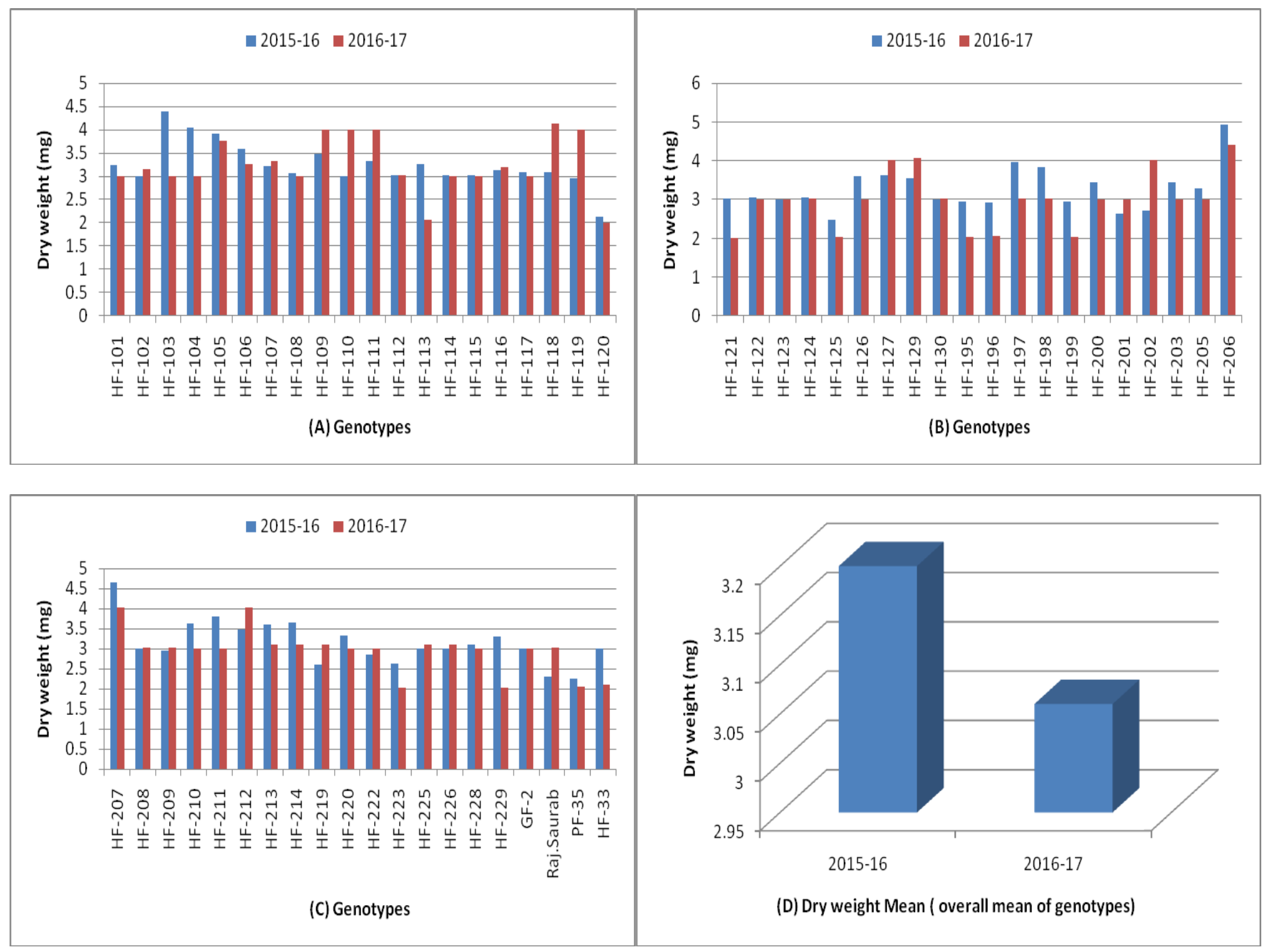


\section{Int.J.Curr.Microbiol.App.Sci (2017) 6(10): 4970-4980}

Fig.5 Vigour index-I of genotypes (A, B, C) and overall mean of genotypes (D)
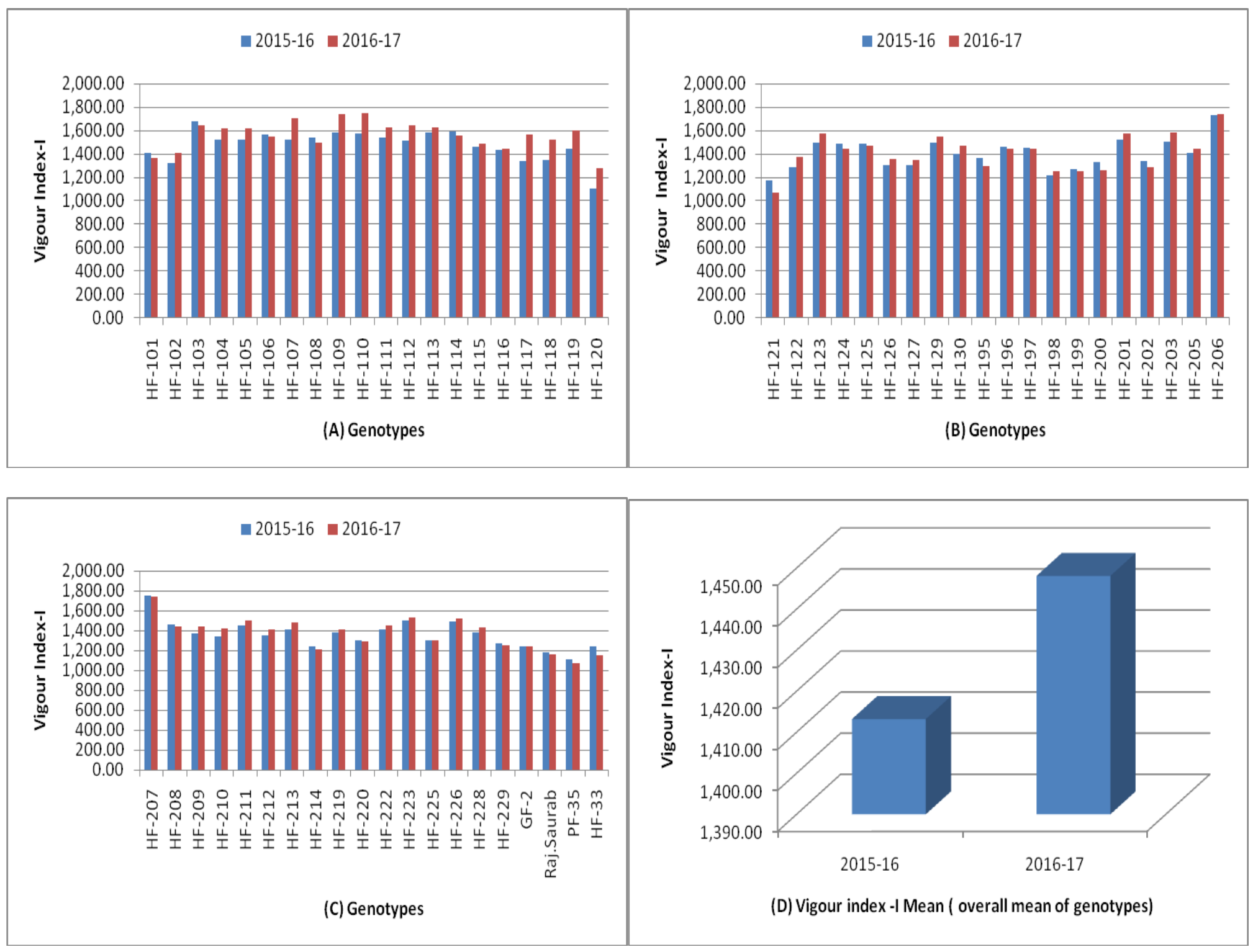


\section{Int.J.Curr.Microbiol.App.Sci (2017) 6(10): 4970-4980}

Fig.6 Vigour inndex-II of genotypes (A, B, C) and overall mean of genotypes (D)
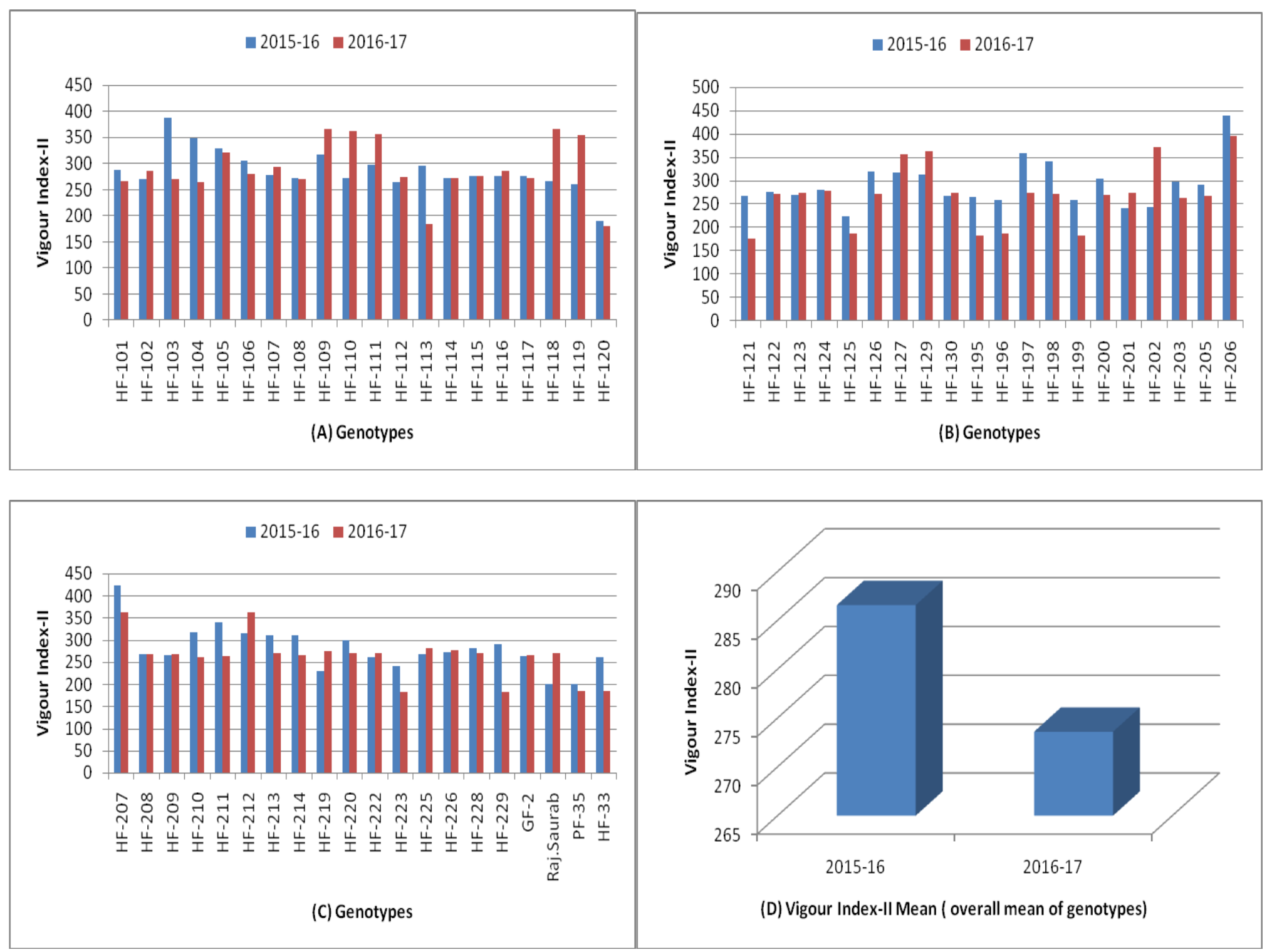
Similarly, seed vigour index-II was maximum in HF-206(368) and the minimum seed vigour index-II (185.67) was recorded in HF-120 (fig-6). Wani et al., (2013) revealed that seed vigour index is strongly under genetic control and highest heritability accompanied with genetic advance was observed in seed vigour index.

The use of genotype with vigorous seed is pre-requisite for successful adoption, production and improvement of any crop, because the variety with quality seed determines the beneficial effects of other production inputs. The differences in the seed viability and vigour are a function of complex interaction of genetic constitution and environmental factors. Overall, it is concluded that variation in genotypes in respect of different vigour parameters resulted due to physiological, biochemical and genetical differences in genotypes of fennel.As physiological and biochemical differences controlled by genetic constitution of plant, therefore, ultimately plants genetic constitution is responsible for all such differences in genotypes. However, best (HF116, HF-124, HF-206, HF-207) genotypes can be undertaken as a carryover seed and also seed material for further breeding programme.

\section{References}

Abdul-Baki, A.A and Anderson, J.D. 1973. Vigour determination in soyabean seed by multiple criteria. Crop Science, 13: 630-633.

Afshari, H., Eftekhari, M., Faraji, M., Ebadi, A.G. and Ghanbarimalidareh, A. (2011). Studying the effect of 1000grain weight on the sprouting of different species of Salvia L. grown in Iran. Journal of Medicinal Plants Research. 5(16): 3991-3993.

Bailly, C. (2004). Active oxygen species and antioxidants in seed biology. Seed Science and Research. 14: 93-107.

Carvalho, N.M., Nakagawa, J. (1983). Sementes: ciencia, tecnologia e producao. 2.ed. Campinas: Fundacao Cargill. $429 \mathrm{p}$.

El-Alwadi M.E and Esmat, A.H.(2010). Physiological responses of fennel (Foeniculum vulgare Mill) plants to some growth substances. Journal of American Science, 6, 985-991.

Fleener, B. and Smith, S. (1983). Pioneer corn description system, Pioneer Technology Bulletin., 1983:1-60.

ISTA 2003.International Rules for Seed Testing ED. 2003, International Seed Testing Association, Zurich, Switzerland

Kapoor, N., Arya, A., Siddiqui, M.A., Amir, A. and Kumar, H. 2010. Seed deterioration in chickpea (Cicer arietnum L.) under accelerated ageing. Asian Journal of Plant Science. 9(3): 158-162.

Kaya, M., Kaya, G., Kaya, M.D., Atak, M., Saglam, S., Khawar, K.M. and Ciftci, C.Y. (2008). Interaction between seed size and $\mathrm{NaCl}$ on germination and early seedling growth of some Turkish cultivars of chickpea (Cicer arietinum L.). Journal of Zhejiang University of Science. 9: 371-377.

Lucinewton,S., Raul, N., Carvalho, J., Mirian,, B., Lin, C., and Angela, A. (2005). Supercritical fluid extraction from fennel (Foeniculum vulgare Mill) global yield composition and kinetic data.J. of Supercritical Fluilds, 35,212219.

Milberg, P., Anderson, L., Elfverson, C., Regner, S. (1996). Germination characteristics of seeds differing in mass. Seed Science Research. 6: 191197.

Miranldi E.1999. Comparision of the essential oil from ten Foeniculum vulgare Miller 
samples of fruits of different origin. Flavour and Fragrance J., 14:379-382

Pereira, R.S., Nascimento, W.M., Vierira, J.V. (2008). Carrot seed germination and vigor in response to temperature and umbel orders. Scientific Agriculture. 65: 145-150.

Sengupta, Debabrata. 2011. Characterization of fenugreek genotypes/cultivars by field and laboratory techniques. M Sc. Thesis, CCS Haryana Agricultural University, Hisar, Haryana, India.

Sephidkon F. 2001. Evalution of quantitative and qualitative of fennel (Foeniculum vulgare) essential oil in different stages.Iran. J. Med. Aroma. Plants, 4: $85-101$.

Sidhawani, S.K.1991. Use of certified seeds and its contribution towards productivity. In seminar seed industry in Haryana, present at September 1213,1991, CCS HAU, Hisar

Soltani, A., Galeshi, S., Zeinali, E. and Latifi, N. (2002). Germination, seed reserve utilization and seedling growth of chickpea as affected by salinity and seed size. Seed Science Technology. 30(1): 51-60.

Tanuj, 2014. Characterization of fennel genotypes (Foeniculum vulgare Mill) M Sc. Thesis, CCS Haryana Agricultural University, Hisar, Haryana, India

Wani, B.A., Ram, M., Yasin, A., Ali, M., Pandith, A. and Mir, R.A. 2013. Seedling vigour in wheat (Triticum aestivum L.) as a source of genetic variation and study of its correlation with yield and yield components. African Journal of Agricultural Research. 8(4): 370-372.

Yadav.S. 2016. Genotypic Characterization and seed vigour assessment of coriander (Coriandrum sativum L.) Ph.D. Thesis. Department of Vegetable Science, CCS Haryana Agricultural University. Hisar Zoubiri, S., Baaliouamer. A, Seba.N., Chamouni N. (2014). Chemical composition and larvicidal activity of Algerian Foeniculum vulgare Seed essential oil. Arab J. Chem. 7(4):480485.

\section{How to cite this article:}

Sumit Deswal, V.S. Mor, T.P. Malik, S.K. Tehlan and Srikanth Mekala. 2017. Seed Quality and Vigour Assessment of Fennel (Foeniculum vulgare L.) Genotypes. Int.J.Curr.Microbiol.App.Sci. 6(10): 4970-4980. doi: https://doi.org/10.20546/ijcmas.2017.610.471 